\title{
Mitochondrial gene heterogeneity of the bat soft tick Argas vespertilionis (Ixodida: Argasidae) in the Palaearctic
}

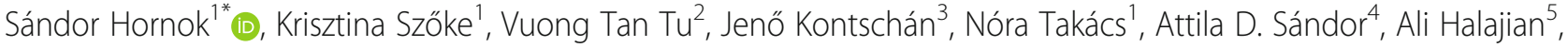 \\ Gábor Földvári ${ }^{1}$, Péter Estók ${ }^{6}$, Olivier Plantard ${ }^{7}$, Sara Epis ${ }^{8}$ and Tamás Görföl ${ }^{9}$
}

\begin{abstract}
Background: Recently, a high degree of mitochondrial gene heterogeneity was demonstrated between conspecific ixodid ticks of bats in Eurasia. Argas vespertilionis is a soft tick species of mainly vespertilionid bats, also with a wide distribution in the Old World. The aim of this study was to investigate the morphology, mitochondrial gene heterogeneity and host range of $A$. vespertilionis in the Old World.

Results: Altogether 318 soft tick larvae were collected from 17 bat species (belonging to six genera) in seven countries. Based on the general morphology (setal arrangement) of $314 \mathrm{~A}$. vespertilionis larvae, and the detailed measurements of fifteen larvae, only minor morphological differences (in dorsal plate size and the type of serrate setae) were observed between specimens from Europe and Vietnam. On the other hand, cytochrome c oxidase subunit 1 (cox1) and 16S rRNA gene sequence analyses of 17 specimens showed that $A$. vespertilionis from Europe is genetically different (with up to 7.5\% cox1 and 5.7\% 16S rRNA gene sequence divergence) from specimens collected in Vietnam, and their phylogenetic separation is well supported.

Conclusion: In its evaluated geographical range, no larval phenotypic differences justify the existence of separate species under the name $A$. vespertilionis. However, phylogenetic analyses based on two mitochondrial markers suggest that it represents a complex of at least two putative cryptic species. The broad host range of $A$. vespertilionis might partly explain its lower degree of mitochondrial gene heterogeneity in comparison with ixodid bat tick species over the same geographical region of Eurasia.
\end{abstract}

Keywords: Soft tick, Chiroptera, Phylogeny, Phylogeography, Cryptic species

\section{Background}

Soft ticks (Acari: Ixodida: Argasidae) include approximately 200 species that are obligate haematophagous ectoparasites of hosts from all classes of terrestrial vertebrates. Argas vespertilionis is a cosmopolitan soft tick species of mainly vespertilionid bats (especially Pipistrellus spp.), with a wide distribution in the Old World, from the Palaearctic to South Africa [1]. Apart from bats, A. vespertilionis was reported to feed on humans $[1,2]$ and domestic animals [3]. This soft tick species is a potential

\footnotetext{
*Correspondence: hornok.sandor@univet.hu

'Department of Parasitology and Zoology, University of Veterinary Medicine, Budapest, Hungary

Full list of author information is available at the end of the article
}

vector of zoonotic viruses [3] and bacteria [4], and the piroplasm Babesia vesperuginis [5].

The taxonomy of the Argasidae is controversial, because the majority of soft tick species can be assigned to more than one genus [6]. Accordingly, the taxonomical status of $A$. vespertilionis also appears to be uncertain. It was originally the type species of the genus Carios [7], but in the most recent list of valid tick names it is mentioned as a member of the genus Argas [8]. Recent phylogenetic analyses do not support $A$. vespertilionis as a member of the genus Argas, as this species has been misplaced into the subfamily Argasinae [9], and based on its $12 \mathrm{~S}$ rRNA gene it should belong to Ornithodorinae [6]. In addition, the homogeneity of $A$. vespertilionis on the species level has long been questioned [7]. 
Recently, high degree of mitochondrial gene heterogeneity was demonstrated between conspecific ixodid ticks of bats in Eurasia [10]. The aim of this study was to investigate $A$. vespertilionis in the same context, i.e. its morphology, mitochondrial gene heterogeneity and host range in the Old World.

To date, molecular analyses of soft ticks focused on the $16 \mathrm{~S}$ rRNA gene, which has the potential for resolving phylogenetic relationships among closely related species in Argasidae [6]. In addition to this gene, the 5' region of the mitochondrial cytochrome $c$ oxidase subunit 1 (cox1) gene was chosen for phylogenetic analysis of $A$. vespertilionis in the present study, because it is regarded as the standard marker for tick species identification by DNA barcoding [11], and is particularly suitable to track separation among soft tick species [12]. Since there are few soft tick cox1 reference sequences in GenBank, a South African isolate of $A$. transgariepinus and a neotropical isolate of an Ornithodoros sp. were also included in the cox 1 phylogenetic analysis. The nomenclature used in the manuscript complies with the valid tick names listed by Guglielmone et al. [8], who follow Hoogstraal in his classification of the Argasidae, although that classification, including the re-assignment of Carios as a subgenus of Argas, has never been supported by any analysis using actual data.

\section{Methods}

\section{Sample collection and morphological analyses}

Soft ticks were collected from bats captured for ringing and monitoring purposes (Table 1). All ticks were stored in $70 \%$ ethanol. Morphological identification was based on the description of $A$. vespertilionis and A. transgariepinus larvae by Hoogstraal [7, 13], and of Ornithodoros larvae (on the genus level) according to Barros-Battesti et al. [14], and Jones \& Clifford [15]. Structures of representative specimens from each country (A. vespertilionis: eight larvae from Vietnam, three larvae from Italy, four larvae from Romania; except $A$. vespertilionis from Kenya, which was damaged) were measured under a Jenaval light microscope (Carl Zeiss GmbH, Jena, Germany) after clearance with lactic acid. The means of these data sets were compared by using two-tailed Student's $t$-test, and were considered significantly different if $P<0.05$.

\section{DNA extraction, molecular and phylogenetic analyses}

DNA was extracted from the larvae with the QIAamp DNA Mini Kit (Qiagen, Hilden, Germany) according to the manufacturer's instruction, including an overnight digestion in tissue lysis buffer with $6.6 \%$ Proteinase- $\mathrm{K}$ at $56{ }^{\circ} \mathrm{C}$. Twenty DNA extracts were used in this study for molecular analyses (eight from Hungary, two from Romania, three from Italy, four from Vietnam, one from
Kenya, one from South Africa and one from Mexico). From these samples two mitochondrial markers were amplified: a $710 \mathrm{bp}$ long fragment of the cytochrome $c$ oxidase subunit 1 (cox1) gene, and an approx. $460 \mathrm{bp}$ part of the 16S rRNA gene, as reported [16].

PCR products were visualized in 1.5\% agarose gel. Purification and Sanger dideoxy sequencing (twice for each sample) were done by Biomi Inc. (Gödöllő, Hungary). Obtained sequences were manually edited, then aligned and compared to reference GenBank sequences by nucleotide BLASTN program (https://blast.ncbi.nlm.nih.gov). Representative sequences were submitted to GenBank (see accession numbers in Table 1). The MEGA model selection method was applied to choose the appropriate model for phylogenetic analyses. In the phylogenetic analyses reference sequences with high coverage (i.e. $98-100 \%$ of the region amplified here) were retrieved from GenBank, and trimmed to the same start and stop positions (cox1: 652 bp in length, 16S rRNA gene: 439-442 bp in length). This dataset was resampled 1,000 times to generate bootstrap values. Phylogenetic analyses were conducted with the Maximum Likelihood method and Tamura-Nei model by using MEGA version 6.0.

\section{Results}

Altogether 318 soft tick larvae were collected from 17 bat species (belonging to six genera) in seven countries. All, except four soft tick larvae, were morphologically identified as A. vespertilionis (Table 1 ). The majority of $A$. vespertilionis larvae (59.1\%: 188 out of 318, CI: 53.5-64.6\%) were found on Pipistrellus spp. (Table 1). Myotis alcathoe is a new host for this soft tick species.

One specimen from South Africa was identified as $A$. transgariepinus (based on idiosomal setae, palpal articles, coxae and tarsus I). Three larvae from Mexico represented the genus Ornithodoros (based on the elongated piriform dorsal plate with non-parallel sides), but could not be identified on the species level because of the lack of hypostome.

Measurements of selected, diagnostically important structures of $A$. vespertilionis larvae revealed no significant differences between specimens from Europe and Vietnam (Table 2), except for the length and width of the dorsal plate (plate length of ticks from Italy/Romania vs Vietnam: $t=3.49, d f=13, P=0.004$; plate width of ticks from Italy/Romania $v s$ Vietnam: $t=3.21, d f=13$, $P=0.006)$. Dorsal plate shape index (length:width ratio), as well as hypostome shape and dentition (4/4 anteriorly, $2 / 2$ behind apex) were not significantly different between these categories. Sternal and anal setae were consistently pointed (needle-like), whereas dorsal setae were serrate. The morphology of serrate setae showed minor difference between geographically distant specimens (Fig. 1): larvae from Europe had separated surface protrusions in the 
Table 1 Host species, place of collection and GenBank accession numbers for sequences from soft ticks used in this study

\begin{tabular}{|c|c|c|c|c|c|}
\hline Species & Stage $(n)$ & Host species & Country (Locality) & $\operatorname{cox} 1$ & 16S rRNA \\
\hline \multirow[t]{31}{*}{ Argas vespertilionis } & larva (58) & Pipistrellus pygmaeus & Hungary (Mezőföld) & KX431953 & KX831484 \\
\hline & larva (5) & Myotis alcathoe & Hungary (Bakony) & KX431955 & KX831486 \\
\hline & larva (12) & Eptesicus serotinus & Hungary (Béda) & - & - \\
\hline & larva (15) & Pipistrellus pygmaeus & Hungary (Dráva) & - & - \\
\hline & larva (1) & Pipistrellus kuhlii & Hungary (Dráva) & - & - \\
\hline & larva (27) & Plecotus austriacus & Hungary (Dráva) & KX431954 & KX831485 \\
\hline & larva (6) & Myotis dasycneme & Hungary (Gemenc) & - & - \\
\hline & larva (58) & Pipistrellus nathusii & Hungary (Gemenc) & - & - \\
\hline & larva (10) & Pipistrellus pygmaeus & Hungary (Gemenc) & - & - \\
\hline & larva (1) & Pipistrellus pipistrellus & Hungary (Kecső) & KX431954 & KX831489 \\
\hline & larva (2) & Eptesicus serotinus & Hungary (Mecsek) & - & - \\
\hline & larva (1) & Myotis alcathoe & Hungary (Mecsek) & - & - \\
\hline & larva (18) & Myotis brandtii & Hungary (Mecsek) & - & - \\
\hline & larva (27) & Myotis dasycneme & Hungary (Mecsek) & - & - \\
\hline & larva (4) & Nyctalus noctula & Hungary (Mecsek) & - & - \\
\hline & larva (1) & Plecotus auritus & Hungary (Mecsek) & - & - \\
\hline & larva (5) & Pipistrellus pipistrellus & Hungary (Mecsek) & - & - \\
\hline & larva (1) & Pipistrellus pygmaeus & Hungary (Mecsek) & - & - \\
\hline & larva (19) & Vespertilio murinus & Hungary (Miskolc) & - & - \\
\hline & larva (1) & Myotis alcathoe & Hungary (Nagyvisnyó) & - & - \\
\hline & larva (1) & Pipistrellus pipistrellus & Hungary (Nagyvisnyó) & - & - \\
\hline & larva (1) & Pipistrellus pipistrellus & Hungary (Noszvaj) & - & - \\
\hline & larva (1) & Pipistrellus pipistrellus & Hungary (Ócsa) & KX431953 & KX831488 \\
\hline & larva (2) & Vespertilio murinus & Hungary (Sopron) & KX431953 & KX831487 \\
\hline & larva (2) & Eptesicus serotinus & Romania (Somova) & KX431954 & KX831490 \\
\hline & larva (9) & Pipistrellus pipistrellus & Romania (Salciua) & - & - \\
\hline & larva (6) & Pipistrellus pipistrellus & Italy (Bergamo) & KX431953-KX431954 & KX831496-KX831498 \\
\hline & larva (7) & Pipistrellus javanicus & Vietnam (Can Gio) & KX431957 & KX831492 \\
\hline & larva (3) & Pipistrellus cf. abramus & Vietnam (Thanh Hoa) & KX431958 & KX831493 \\
\hline & larva (9) & Pipistrellus cf. abramus & Vietnam (Bach Long Vi) & KX431959-KX431960 & KX831494-KX831495 \\
\hline & larva (1) & Pipistrellus cf. rueppellii & Kenya (South Horr) & KX431956 & KX831491 \\
\hline Argas transgariepinus & larva (1) & Pipistrellus hesperidus & South Africa (Makhado) & KX431961 & - \\
\hline Ornithodoros sp. & larva (3) & Balantiopteryx plicata & Mexico (Chiapas) & KX431962 & KX831499 \\
\hline
\end{tabular}

upper half of setae, but those from Vietnam had grouped (tuft-like) fragmentation of the setal end.

Sequencing of the cox 1 gene fragment was successful in the case of 17 samples (Table 1; Fig. 2). Argas vespertilionis cox1 sequences showed 0-2 nucleotide (0-0.3\%) differences, i.e. 99.7-100\% (650-652/652 bp) similarity between isolates from Hungary, Romania and Italy. Haplotypes from Europe had 37-38 nucleotide (5.7-5.8\%) differences from an $A$. vespertilionis larva collected in Kenya, meaning 94.2-94.3\% (614-615/652 bp) similarity with the latter. There was a more pronounced sequence divergence between specimens of $A$. vespertilionis from Europe and Vietnam, amounting to 46-49 nucleotide (7.1-7.5\%) differences, i.e. only 92.5-92.9\% (603-606/652 bp) similarity. The cox 1 sequences of $A$. vespertilionis from Vietnam had 2-15 nucleotide (0.3-2.3\%) differences from each other, amounting to $97.7-99.7 \%$ (637-650/652 bp) similarity, i.e. were more heterogeneous within Vietnam than between samples from three European countries. The topology of the cox 1 phylogenetic tree reflected the above differences (with high support of separation of $A$. vespertilionis haplotypes both within Vietnam, and between Hungary and 
Table 2 Measurements, i.e. size range (mean value) of selected structures with diagnostic importance in the case of Argas vespertilionis larvae from three geographical regions

\begin{tabular}{|c|c|c|c|c|}
\hline & & Italy $(n=3)$ & Romania $(n=4)$ & Vietnam $(n=8)$ \\
\hline \multirow[t]{6}{*}{ Idiosoma dorsum } & Anterolateral setae (4th) & $35-44(38.3)$ & $31-44(37.8)$ & $35-48(42.3)$ \\
\hline & Central setae (3rd) & $31-45(37.8)$ & $38-41(39.5)$ & $33-41(37.6)$ \\
\hline & Posterolateral setae (4th) & $51-61(56.8)$ & $55-65(61.8)$ & $56-71(64)$ \\
\hline & Dorsal plate length & $200-208(203.3)^{a}$ & $194-211(204.8)^{\mathrm{a}}$ & $193-201(196.3)^{\mathrm{b}}$ \\
\hline & Dorsal plate width & $100-111(106.3)^{a}$ & $101-113(108.3)^{\mathrm{a}}$ & $99-105(101)^{b}$ \\
\hline & Dorsal plate ratio length:width & $1.85-2(1.92)$ & $1.87-1.92(1.89)$ & $1.91-1.98(1.94)$ \\
\hline \multirow[t]{5}{*}{ Idiosoma venter } & Sternal setae (3rd) & $25-27(25.8)$ & 23-30 (27.8) & 20-35 (25.8) \\
\hline & Circumanal setae (1st) & 30-31 (30.3) & 28-30 (29.3) & 30-33 (30.8) \\
\hline & Circumanal setae (2nd) & $35-36(35.3)$ & 34-35 (34.8) & $33-37(35)$ \\
\hline & Anal valve setae & $32-38(35)$ & $32-38(34.8)$ & $35-39(37)$ \\
\hline & Posteromedian setae & 23-29 (25.8) & $25-28(27)$ & $25-30(27.5)$ \\
\hline \multirow[t]{5}{*}{ Capitulum } & Post-hypostomal setae & 10-18 (13.8) & $11-14(12.3)$ & 10-15 (11.9) \\
\hline & Palpal length & $165-180(173.3)$ & 174-176 (175) & $165-176(170.3)$ \\
\hline & Hypostome length* & $125-130(127.5)$ & - & $124-125(124.5)$ \\
\hline & Hypostome width (anterior)* & 30-31 (30.5) & - & $31-35(33)$ \\
\hline & Hypostome width (posterior)* & $36-39(37.5)$ & - & 39-40 (39.5) \\
\hline \multirow[t]{2}{*}{ Legs } & Tarsus I length & $125-135$ (129) & $124-139(128.3)$ & $130-137(132.8)$ \\
\hline & Longest seta of tarsus I (near Haller's organ) & $36-45(42.5)$ & $43-47(44.8)$ & $38-55(46.5)$ \\
\hline
\end{tabular}

Lengths are provided in $\mu \mathrm{m}$, rounded to decimals (except for dorsal plate ratio). Values within a row having different superscript letters are significantly different *Most larvae had broken hypostome; only two specimens from Italy and two from Vietnam allowed measurements

Vietnam). Clustering of $A$. vespertilionis isolates with two members of Ornithodorinae received moderate $(72 \%)$ support (Fig. 2).

Concerning the amplified part of the 16S rRNA gene, this was successfully sequenced from 16 samples. Argas vespertilionis had up to four nucleotide $(0.9 \%)$ differences $(437 / 441 \mathrm{bp}=99.1 \%$ similarity) between European haplotypes, whereas these had 20 nucleotide (4.5\%) differences from the $A$. vespertilionis larva collected in Kenya $(420 / 440 \mathrm{bp}=95.5 \%$ similarity), and 25 nucleotide (5.7\%) differences $(416 / 441 \mathrm{bp}=94.3 \%$ similarity) from $A$. vespertilionis larvae from Vietnam. The $16 \mathrm{~S}$ rRNA gene sequences of $A$. vespertilionis from Vietnam had up to six nucleotide (1.4\%) differences from each other, i.e. 98.6\% (436/442 bp) similarity. Based on the 16S rRNA phylogenetic tree (Fig. 3), the separation of $A$. vespertilionis from Europe vs Kenya/Vietnam was highly supported

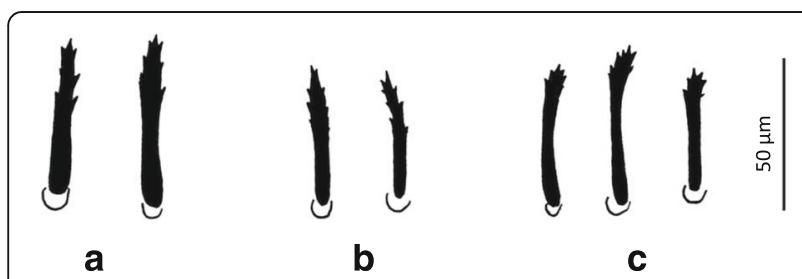

Fig. 1 Schematic drawings of differences between serrate setae of Argas vespertilionis larvae from Romania (a), Italy (b) and Vietnam (c)
(99\%); A. vespertilionis was placed outside Argasinae, but its relationships among Ornithodorinae were only weakly supported (Fig. 3).

\section{Discussion}

In this study $314 A$. vespertilionis larvae were collected and morphologically investigated. Finding of only larvae of soft ticks on bats is in line with the life cycle of $A$. vespertilionis, i.e. larvae (unlike nymphs and adults) suck blood for several weeks on their bat hosts (14-31 days: [1]), therefore almost exclusively these can be collected from bats. In the present study $A$. vespertilionis was found on 15 bat species, most of which are already reported hosts (including four Pipistrellus spp., seven Myotis spp. and two Eptesicus, as well as two Nyctalus spp. $[17,18])$.

While $A$. vespertilionis is mentioned in the most recent list of valid tick names as a member of the genus Argas [8], morphological and phylogenetic analyses do not support this assumption [6,9]. Instead, based on its 12S rRNA gene, $A$. vespertilionis was demonstrated to belong to Ornithodorinae [6]. Phylogenetic analyses of the present study also reflected that haplotypes of $A$. vespertilionis clustered outside the Argasinae.

During the past few decades scientific debate tried to establish morphological features suitable to solve the taxonomical uncertainty among the Argasidae. In the 


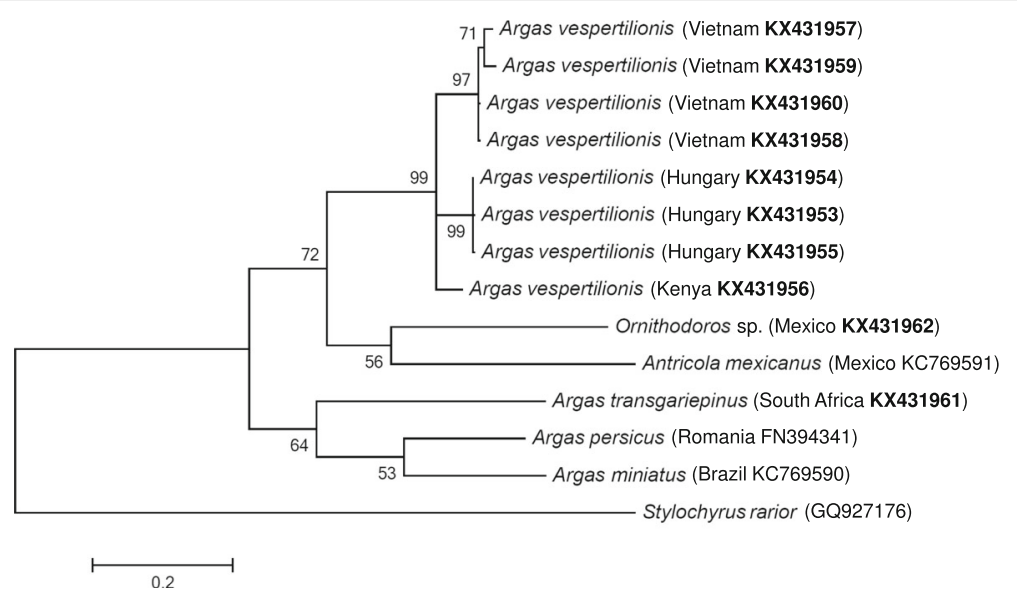

Fig. 2 Phylogenetic relationships of Argas vespertilionis (collected in Hungary, Kenya and Vietnam) and other soft tick species, based on the cytochrome c oxidase subunit 1 (cox1) gene. Cox1 sequences of A. vespertilionis from Romania and Italy were identical with those from Hungary, therefore are not shown. Accession numbers of sequences from this study are highlighted in bold. Branch lengths represent the number of substitutions per site inferred according to the scale shown

larval stage the number of setae according to anatomical location is an important feature to recognize genera [14], and the shape of dorsal plate, the morphology of hypostome and the length of setae may be used to distinguish closely related species $[15,19]$.

The possibility that more than one species exist under the name $A$. vespertilionis has already been suggested by Hoogstraal [7], but this remained hitherto unevaluated. In this study the great majority of relevant parameters were not significantly different between $A$. vespertilionis larvae from Europe and Vietnam, although these larvae proved to be well separated based on two mitochondrial genetic markers. Similarly, in a previous study comparing neotropical bat soft ticks, selected measurements (length of certain setae) differed slightly between larvae from different countries, but these were considered to represent the same species [19]. Intraspecific variations in body outline of $A$. vespertilionis have also been reported [7]. Furthermore, despite the differences in the mean length and width of the dorsal plate between $A$. vespertilionis from Europe and Vietnam, as demonstrated here, these alone cannot serve to delineate species, because the shape of the dorsal plate (reflected here by similar length:width ratios) is regarded as more relevant in this context $[15,19]$.

A minor difference was also observed between the serrate setae of $A$. vespertilionis larvae collected in distant regions of Eurasia. However, while the types of fringed setae were reported to be different between larvae of closely related Ornithodoros spp. [15], the latter were also shown to differ in the ranges of their setal lengths and hypostome (unlike $A$. vespertilionis larvae here). Therefore, in the absence of further distinguishing characteristics, the present data suggest that $A$. vespertilionis in Europe and Vietnam belong to the same species, and observed minor differences (i.e. dorsal plate size) should be interpreted as intraspecific variations between populations. The morphology of specimens analyzed in this study also suggests that they are conspecific with $A$. vespertilionis reported from Japan [20].

On the other hand, specimens from Europe and Vietnam had cox 1 sequence divergence (7.1-7.5\%) exceeding that proposed for closely related ixodid tick species $(6 \%$, see [11]). Accordingly, morphologically similar, but genetically distinct populations of $A$. vespertilionis exist in Europe and Southeast Asia, suggesting that this soft tick should be regarded as a complex (group) of at least two putative cryptic species. This seems to be justified from the morphology of the larval stage alone (because differences between argasid larvae served to describe new soft tick species, e.g. in [15]), but morphological investigation of adult specimens from both regions and molecular/phylogenetic analyses of nuclear markers (18S and 28S rRNA genes) should ultimately confirm this conclusion.

Compared in the same context, the sequence divergence between $A$. vespertilionis from Kenya and Europe was less pronounced than between samples from Europe and Vietnam, suggesting that genetic exchange has been more likely in this direction (although a larger sample size from sub-Saharan Africa is needed to draw final conclusion in this respect). In support of this possibility, some of the main hosts of $A$. vespertilionis in the present study, most notably Pipistrellus nathusii is known to migrate long distances (up to $1,900 \mathrm{~km}$ ) in the northeastern to south-western direction [21]. Another 


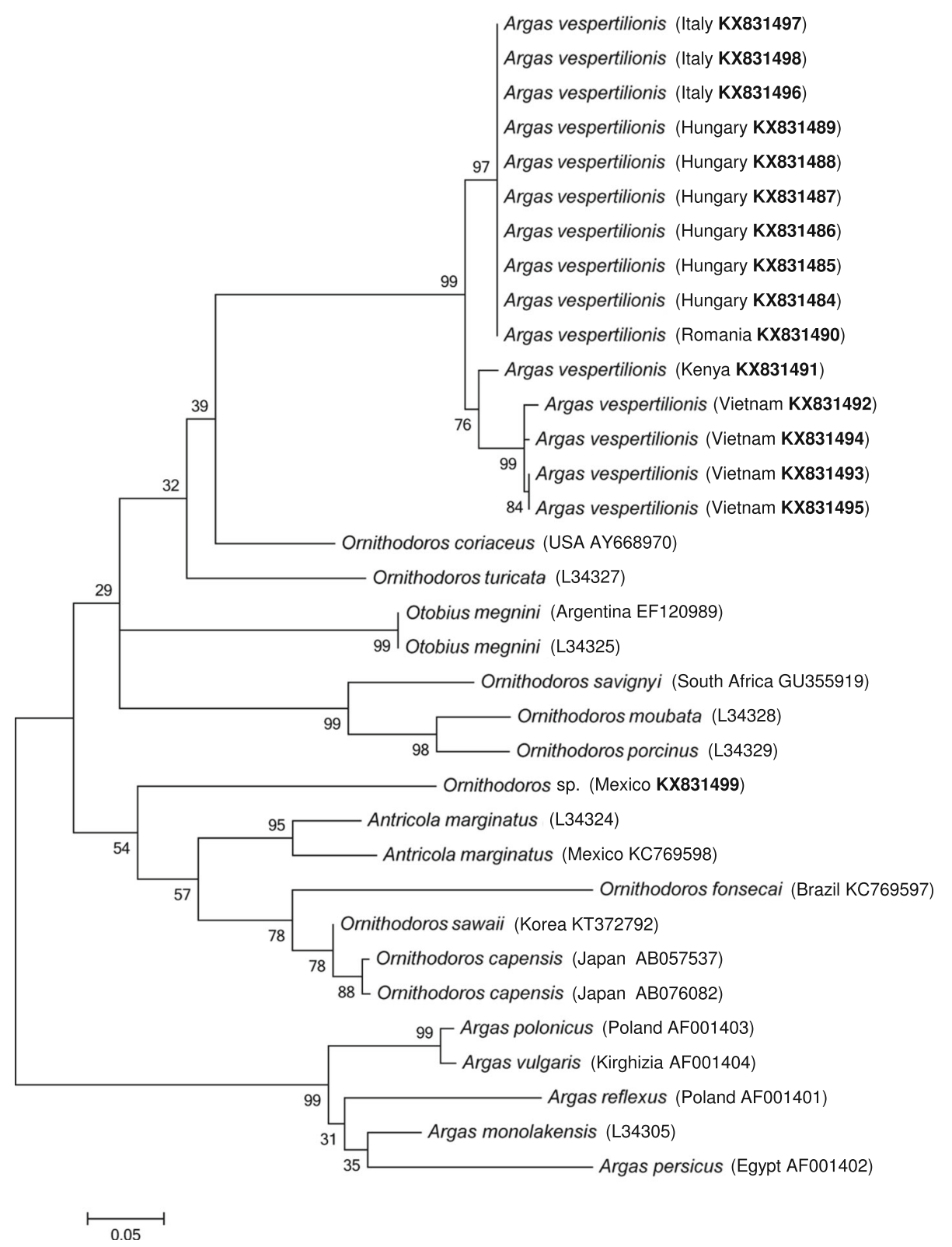

Fig. 3 Phylogenetic relationships of Argas vespertilionis (collected in five countries), and other soft tick species, based on the 165 rRNA gene. Accession numbers of sequences from this study are highlighted in bold. Branch lengths represent the number of substitutions per site inferred according to the scale shown

important host, $P$. kuhlii is widespread in certain regions across Europe, the Middle-East, North Africa and Asia [22].

In Eurasia, high degree of mitochondrial gene heterogeneity (i.e. up to $16 \% \operatorname{cox} 1$ sequence divergence) has recently been demonstrated between ixodid bat ticks that had been regarded as conspecific [10]. This was explained by the preference of each tick species for bat hosts from a single genus, as well as by the geographical separation of relevant bat host species [10]. In comparison with ixodid bat ticks, the less pronounced difference (in terms of both morphology and genetics) between geographically distant isolates of $A$. vespertilionis, as shown here, may root in the fact that this soft tick species has a broad host spectrum (involving vespertilionid bats from at least six genera, as also shown here), thus preventing complete allopatric separation of its populations.

\section{Conclusions}

In its evaluated geographical range, no larval phenotypic differences justify the existence of separate species under 
the name $A$. vespertilionis. However, phylogenetic analyses based on two mitochondrial markers suggest that it represents a complex of at least two putative cryptic species. The broad host range of $A$. vespertilionis might partly explain its lower degree of mitochondrial gene heterogeneity in comparison with ixodid bat tick species over the same geographical region of Eurasia.

\section{Abbreviations}

cox1: Cytochrome c oxidase subunit 1; df: Degrees of freedom; rRNA: Ribosomal ribonucleic acid

\section{Acknowledgements \\ The survey was organized in the framework of the EurNegVec COST Action TD1303. Financial support was provided by OTKA K112440 and OTKA 115854 (to $\mathrm{SH}$ ) and Domus Hungarica (to ADS). The publication of this research was supported by the 11475-4/2016/FEKUT grant of the Hungarian Ministry of Human Resources. The authors would like to thank the contributions of Dávid Kováts, Sándor Boldogh, Gábor Kemenesi and Anna Horváth to the samples. GF was supported by the János Bolyai Research Scholarship of the Hungarian Academy of Sciences.}

\section{Funding}

Financial support was provided by OTKA K112440, OTKA 115854 and Domus Hungarica.

\section{Availability of data and materials}

The datasets supporting the conclusions of this study are included within the article. The sequences are submitted in the GenBank database under accession numbers KX431953-KX431962 (cox1 gene) and KX831484-KX831499 (16S rRNA gene).

\section{Authors' contributions}

SH initiated and supervised the study, did part of the morphological and genetic comparisons, wrote the manuscript. KS extracted the DNA. VTT, ADS, $\mathrm{AH}, \mathrm{PE}, \mathrm{OP}, \mathrm{SE}$ contributed important samples to the study. JK made Fig. 1, did the phylogenetic analyses and participated in morphological comparisons. NT performed PCRs. GF organized part of the sample collection. TG collected most of the samples. All authors read and approved the final manuscript.

\section{Competing interests}

The authors declare that they have no competing interests.

\section{Consent for publication}

Not applicable.

\section{Ethics approval}

Permission for bat capture was provided by the National Inspectorate for Environment, Nature and Water (Hungary), the Vietnamese Ministry of Agriculture and Rural Development (Vietnam Administration of Forestry) and the Underground Heritage Commission (Romania). Bat banding license numbers are 59/2003 (PE), 305/2015 (ADS) and TMF-493/3/2005 (TG).

\footnotetext{
Author details

${ }^{1}$ Department of Parasitology and Zoology, University of Veterinary Medicine, Budapest, Hungary. ${ }^{2}$ Institute of Ecology and Biological Resources, Vietnam Academy of Science and Technology, Hanoi, Vietnam. ${ }^{3}$ Plant Protection Institute, Centre for Agricultural Research, Hungarian Academy of Sciences, Budapest, Hungary. ${ }^{4}$ Department of Parasitology and Parasitic Diseases, University of Agricultural Sciences and Veterinary Medicine, Cluj-Napoca, Romania. ${ }^{5}$ Department of Biodiversity, School of Molecular and Life Sciences, Faculty of Science and Agriculture, University of Limpopo, Polokwane, South Africa. ${ }^{6}$ Department of Zoology, Eszterházy Károly University, Eger, Hungary. ${ }^{7}$ BIOEPAR, INRA, Oniris, Nantes, France. ${ }^{8}$ Department of Biosciences, University of Milan, Milan, Italy. ${ }^{9}$ Department of Zoology, Hungarian Natural History Museum, Budapest, Hungary.
}

Received: 19 October 2016 Accepted: 15 February 2017

Published online: 28 February 2017

\section{References}

1. Hoogstraal H. Argas vespertilionis. In: African Ixodoidea I. Ticks of the Sudan. Washington DC: Department of the Navy, Bureau of Medicine and Surgery; 1956. p. 104-11

2. Jaenson TG, Tälleklint $L$, Lundqvist $L$, Olsen B, Chirico J, Mejlon $H$. Geographical distribution, host associations, and vector roles of ticks (Acari: Ixodidae, Argasidae) in Sweden. J Med Entomol. 1994;31:240-56.

3. Manzano-Román R, Díaz-Martín V, de la Fuente J, Pérez-Sánchez R. Soft ticks as pathogen vectors: distribution, surveillance and control. In: Manjur Shah M (ed.) Parasitology. 2012. http://www.intechopen.com/. [Accessed 23 June 2016].

4. Socolovschi C, Kernif T, Raoult D, Parola P. Borrelia, Rickettsia, and Ehrlichia species in bat ticks, France, 2010. Emerg Infect Dis. 2012:18:1966-75.

5. Gardner RA, Molyneux DH. Babesia vesperuginis: natural and experimental infections in British bats (Microchiroptera). Parasitology. 1987;95(Pt 3):461-9.

6. Burger TD, Shao R, Labruna MB, Barker SC. Molecular phylogeny of soft ticks (Ixodida: Argasidae) inferred from mitochondrial genome and nuclear rRNA sequences. Ticks Tick Borne Dis. 2014;5:195-207.

7. Hoogstraal H. Bat ticks of the genus Argas (Ixodoidea, Argasidae). 3. The subgenus Carios. A redescription of A. (C.) vespertilionis (Latreille, 1802), and variation within an Egyptian population. Ann Ent Soc Am. 1958;51:19-26.

8. Guglielmone AA, Robbins RG, Apanaskevich DA, Petney TN, Estrada-Pena A, Horak IG, et al. The Argasidae, Ixodidae and Nuttalliellidae (Acari: Ixodida) of the world: a list of valid species names. Zootaxa. 2010:2528:1-28.

9. Klompen JSH, Oliver JH. Systematic relationships in the soft ticks (Acari: Ixodida: Argasidae). Syst Entomol. 1993;18:313-31.

10. Hornok S, Estrada-Peña A, Kontschán J, Plantard O, Kunz B, Mihalca AD, et al. High degree of mitochondrial gene heterogeneity in the bat tick species Ixodes vespertilionis, I. ariadnae and I. simplex from Eurasia. Parasit Vectors. 2015;8:457.

11. Lv J, Wu S, Zhang $Y$, Chen $Y$, Feng $C$, Yuan $X$, et al. Assessment of four DNA fragments (COI, 16S rDNA, ITS2, 12S rDNA) for species identification of the Ixodida (Acari: Ixodida). Parasit Vectors. 2014;7:93.

12. Cruikshank RH. Molecular markers for the phylogenetics of mites and ticks. Exp Appl Acarol. 2002;7:3-14

13. Hoogstraal H. Bat Ticks of the genus Argas (Ixodoidea, Argasidae) 2. Secretargas new subgenus and A. transgariepinus White, 1846, its adult and immature stages; with a definition of the subgenus Argas. Ann Ent Soc Am. 1957;50:544-9.

14. Barros-Battesti DM, Ramirez DG, Landulfo GA, Faccini JHL, Dantas-Torres F, Labruna MB, et al. Immature argasid ticks: diagnosis and keys for Neotropical region. Rev Bras Parasitol Vet. 2013;22:443-56.

15. Jones EK, Clifford CM. The systematics of the subfamily Ornithodorinae (Acarina: Argasidae). V. A revised key to larval Argasidae of the western hemisphere and description of seven new species of Ornithodoros. Ann Ent Soc Am. 1972:65:730-40.

16. Hornok S, Takács N, Szőke K, Kunz B. First record of Ixodes ariadnae in Germany. Acta Vet Hung. 2015;63:347-51.

17. Siuda K, Stanko M, Piksa K, Gorz A. Ticks (Acari: Ixodida) parasitizing bats in Poland and Slovakia. Wiad Parazytol. 2009:55:39-45.

18. Frank R, Kuhn T, Werblow A, Liston A, Kochmann J, Klimpel S. Parasite diversity of European Myotis species with special emphasis on Myotis myotis (Microchiroptera, Vespertilionidae) from a typical nursery roost. Parasit Vectors. 2015;8:101.

19. Venzal JM, Nava S, Terassini FA, Orgrsewalska M, Camargo LMA, Labruna MB. Orntihodoros peropteryx (Acari: Argasidae) in Bolivia: an argasid tick with a single nymphal stage. Exp Appl Acarol. 2013;61:231-41.

20. Yamaguti N, Tipton VJ, Keegan HL, Toshioka S. Ticks in Japan, Korea and Ryukyu islands. Brigham Young Univ Sci Bull Biol Ser. 1971;15:1-226.

21. Hutterer R, Ivanova T, Meyer-Cords C, Rodrigues L. Bat migrations in Europe. A review of banding data and literature, Naturschutz und Biologische Viefalt, vol. 28. Bonn: Federal Agency for Nature Conservation; 2005. p. 162.

22. Bray TC, Mohammed OB, Alagaili AN. Phylogenetic and demographic insights into Kuhl's Pipistrelle, Pipistrellus kuhlii, in the Middle East. PLoS One. 2013;8:e57306 